\title{
INFLUENCE OF DIFFERENT CURRENT DENSITY ON CHARACTERISTICS OF NiFeP NANO ALLOY THIN FILMS
}

\author{
C. Devi ${ }^{1,2, *}$ and R. Ashokkumar ${ }^{3}$ \\ ${ }^{1}$ Research Scholar, Research and Development Centre, Bharathiar University, \\ Coimbatore-641 046, TamilNadu, India \\ ${ }^{2}$ Department of Physics, Jay Shriram Group of Institutions, Avinashipalayam, \\ Tirupur-638660, TamilNadu, India \\ ${ }^{3} \mathrm{PG}$ and Research Department of Physics, Thiruvalluvar Govt. Arts College, \\ Rasipuram-637401, Namakkal, TamilNadu , India \\ *E-mails: deviphd12@gmail.com
}

\begin{abstract}
In this study, electroplated $\mathrm{NiFeP}$ thin films were prepared with different density of current. Characterization of films was analyzed. The X-ray diffraction investigation exhibits that the electro plated NiFeP thin films consist of a face-centered cubic (FCC) phase with diffraction peaks (220), (200) and (111). The EDAX study shows that the maximum nickel content of $80.81 \mathrm{wt} \%$ was received for the density of current $5 \mathrm{~mA} / \mathrm{cm}^{2} \mathrm{~g} / 1$. The weight $\%$ of ferrous decreases while a current density was raised. The SEM result exhibits that NiFeP thin films were shiny and uniformly deposited on the cathode surface. The Vickers Hardness Tester result shows that reduction in hardness by improving current density. Moreover, VSM studies indicate an increase in coercivity of materials and decrease in magnetization by increasing current density.

Keywords: Electro deposition, VSM, Characterization, XRD, Crystal, Magnetization, SEM, and Micro hardness,

○) RASĀYAN. All rights reserved
\end{abstract}

\section{INTRODUCTION}

MEMS components, for example, sensors, microactuators, micromotors and frictionless microgears need the utilization of soft magnetic materials because electromagnetic activated MEMS,NEMS is more steady for high power and vast actuation applications. Additionally, they are less applicable to malfunction when exposed to contrary environments such as dust and humidity and can be stimulated with low-cost voltage controllers. ${ }^{1-4}$ There is a wide range of approaches to deposit and incorporate magnetic materials into MEMS and NEMS. Electrodeposition is a suitable method to achieve the requirements of efficient coating and cost-effective processes. Electrodeposition process has many advantages, such as precisely room temperature process, fast deposition rates, sufficient low energy and ability to use complex geometries with easily handled equipment. Moreover, characteristics of materials can be changed by controlling electrolytic solution compositions and parameters of deposition. Because of these merits, electrodeposited soft magnetic materials, for example, $\mathrm{NiFe}$ and its combination have been largely utilized as recording head materials for hard drive productions. ${ }^{5-6}$ The NiFe thin films are utilized in pulse transformers storage, shielding for low-temperature measurement, a transformer for residual current devices and transducers ${ }^{7-11}$. Among different $\mathrm{Fe}$-based compounds, $\mathrm{Fe}-\mathrm{Ni}$ alloys have pulled great attention not only in the field of technological applications but also in the fundamental research. The utilization of phosphorus with $\mathrm{NiFe}$ prompts to better corrosion resistance, magnetic properties and structural properties of the alloy. ${ }^{12-14}$ In this study, the effects of different current density on NiFeP films were analyzed.

\section{EXPERIMENTAL}

Electrodeposition of $\mathrm{NiFeP}$ composite films were setup with electrolytic baths consisting $\mathrm{FeSO}_{4}(20 \mathrm{~g} / \mathrm{l})$, $\mathrm{NiSO}_{4}(50 \mathrm{~g} / \mathrm{l}), \mathrm{NH}_{4} \mathrm{HCO}_{2}(40 \mathrm{~g} / \mathrm{l}), \mathrm{H}_{3} \mathrm{PO}_{3}(10 \mathrm{~g} / \mathrm{l}), \mathrm{C}_{6} \mathrm{H}_{8} \mathrm{O}_{7}(10 \mathrm{~g} / \mathrm{l})$ with different current density 2,3,4

Rasayan J. Chem., 11(3), 1144-1150(2018)

http://dx.doi.org/10.31788/RJC.2018.1133088

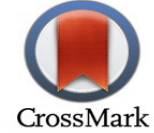


RASĀYAN J. Chem.

Vol. 11 | No. 3 |1144 - 1150 | July - September | 2018

and $5 \mathrm{~mA} / \mathrm{cm}^{2}$. The arrangement $\mathrm{pH}$ was changed in accordance with 6.0 by including $\mathrm{NH} 4 \mathrm{OH}$ and electro deposition was conducted at $30^{\circ} \mathrm{C}$. Electro plating time interval was $15 \mathrm{~min}$. In this study, copper and steel went about as cathode and anode separately with measurement $7.5 \mathrm{~cm} \times 1.5 \mathrm{~cm}^{15-17}$. Following 15 minutes, the cathode plate was detached from an electrolytic bath and dried for a couple minutes. The crystal phase nature and particle size of material deposition were identified and examined by the device X-ray diffractometer (XRD) with $\mathrm{Cu} \mathrm{K}_{-}$radiation. Morphological investigation of Ni-Fe-P films was completed by Scanning Electron Microscope (SEM) and hardness of material deposits was determined by Vickers Hardness Test. The chemical composition of Ni-Fe-P thin films was examined by EDAX (Energy-dispersive X-ray Spectroscopy) and magnetic properties investigated by the device vibrating sample magnetometer. ${ }^{18-22}$

\section{Elemental Composition of NiFeP Thin Films}

\section{RESULTS AND DISCUSSION}

The elemental composition of NiFeP films was found by EDAX analyzer. From result, the ferrous compositions decrease as $22.63 \%, 18.78 \%, 14.92 \%$ and $11.76 \%$ for current density $2,3,4$ and $5 \mathrm{~mA} / \mathrm{cm}^{2}$ respectively. Nickel compositions increase as $67.84 \%, 70.96 \%, 76.32 \%$ and $80.81 \%$ for current density 2 , 3,4 and $5 \mathrm{~mA} / \mathrm{cm}^{2}$ respectively. Phosphorus compositions are as $9.53 \%, 10.26 \%, 8.76 \%$ and $7.43 \%$ for current density 2, 3, 4 and $5 \mathrm{~mA} / \mathrm{cm}^{2}$ respectively. So it is concluded that films with high current density exhibit high nickel content and low ferrous content. Fig 1, 2 and 3 show the variation of ferrous, nickel and phosphorus composition with increasing current density.

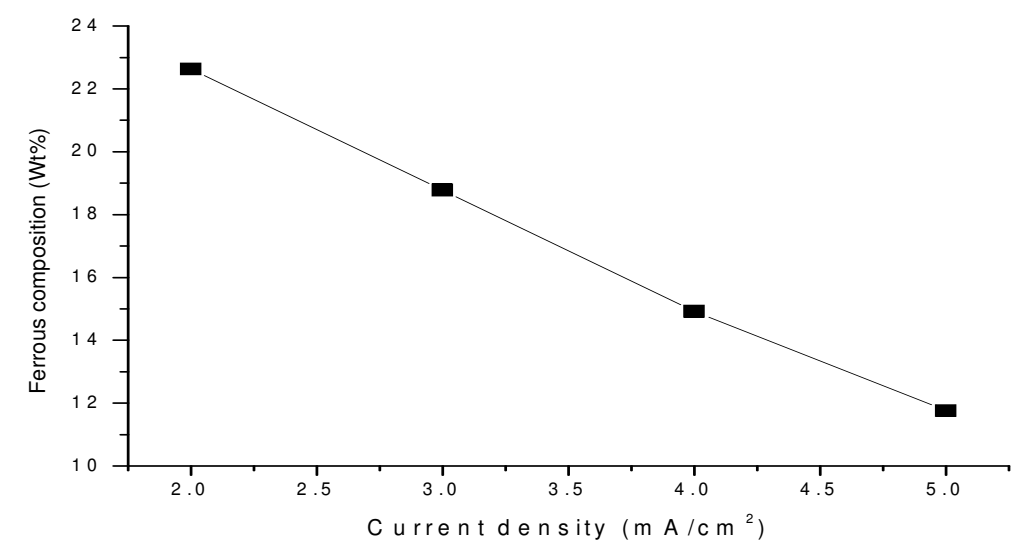

Fig.-1: Current Density Vs Ferrous Composition

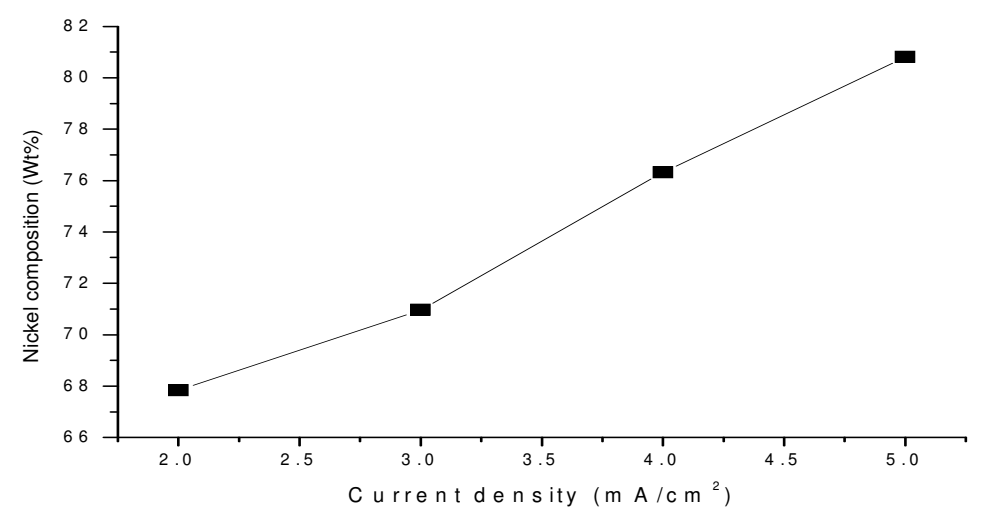

Fig.-2: Current Density Vs Nickel Composition

\section{Morphological Observation}

The surface appearance of NiFeP thin films with increasing current density was analyzed by Scanning Electron Microscope (SEM) images and they are shown in Fig.-4. The coating on the surface is shiny and uniform. Thin films appear crack free. 
RASĀYAN J. Chem.

Vol. 11 | No. 3 |1144 - 1150 | July - September | 2018

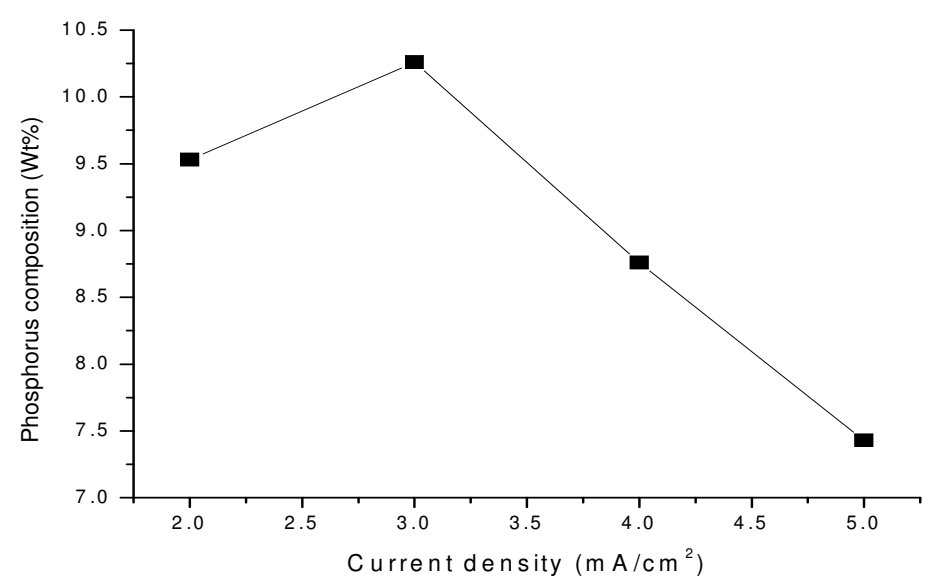

Fig.-3: Current Density Vs Phosphorus Composition

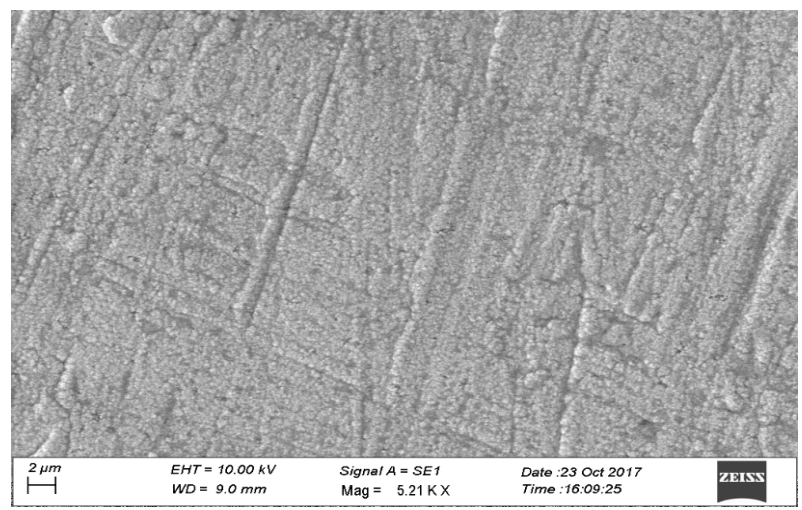

(a)

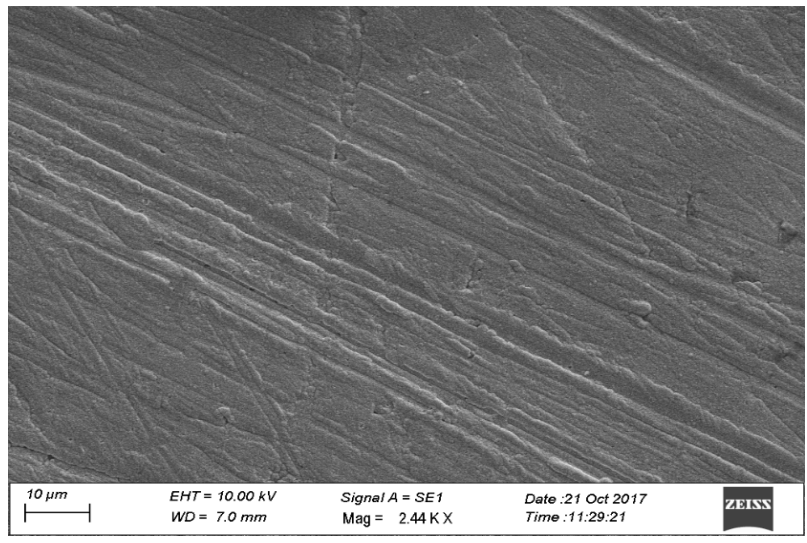

(c)

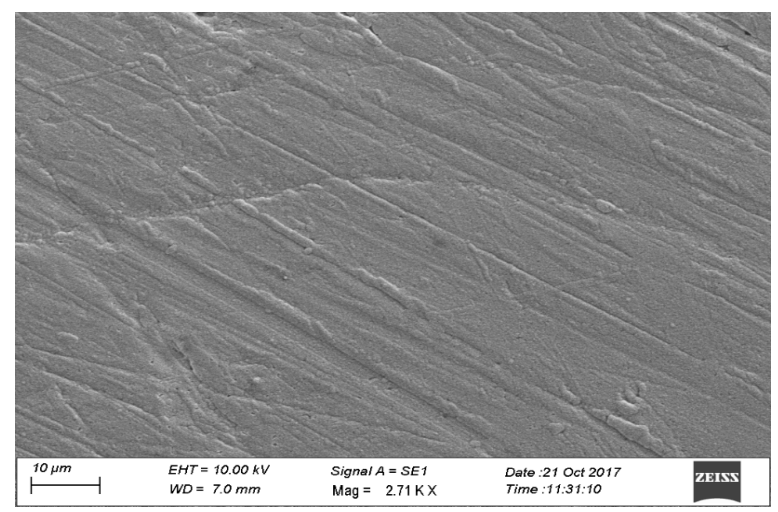

(b)

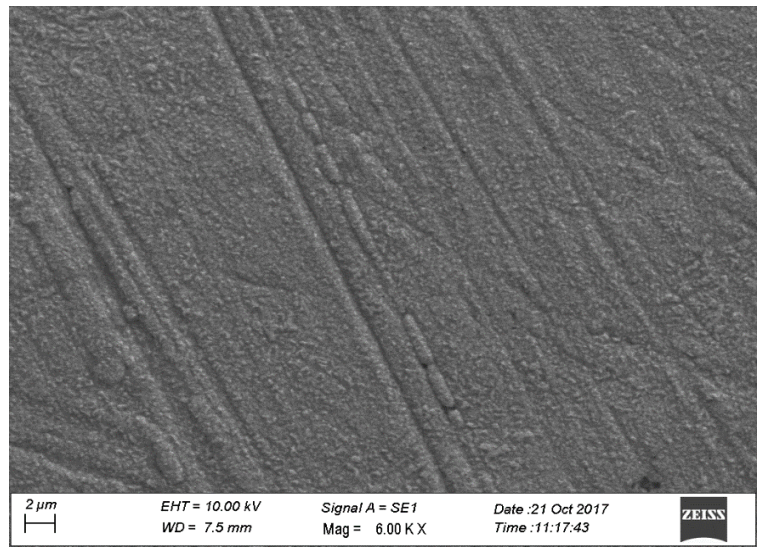

(d)

Fig.-4: SEM images of NiFeP Film for Current Density (a) $2 \mathrm{~mA} / \mathrm{cm}^{2}$ (b) $3 \mathrm{~mA} / \mathrm{cm}^{2}$ (c) $4 \mathrm{~mA} / \mathrm{cm}^{2}$ (d) $5 \mathrm{~mA} / \mathrm{cm}^{2}$

\section{Structural Characters}

Structural characteristic (from XRD Data) data's of thin film materials prepared with distinct current density are shown in figure 5 . The information of crystals in thin film deposition concluded by XRD pattern which is shown in fig 5. FCC phase is the nature of crystals which deposited on subtract. The particle size increases as 30.15, 36.93, 43.73 and $51.09 \mathrm{~nm}$ for current density 2, 3, 4 and $5 \mathrm{~mA} / \mathrm{cm}^{2}$ respectively. The nano crystallite deposits were obtained and the average crystallite size is around $40 \mathrm{~nm}$. 
RASĀYAN J. Chem.

Vol. 11 | No. 3 |1144 - 1150 | July - September | 2018
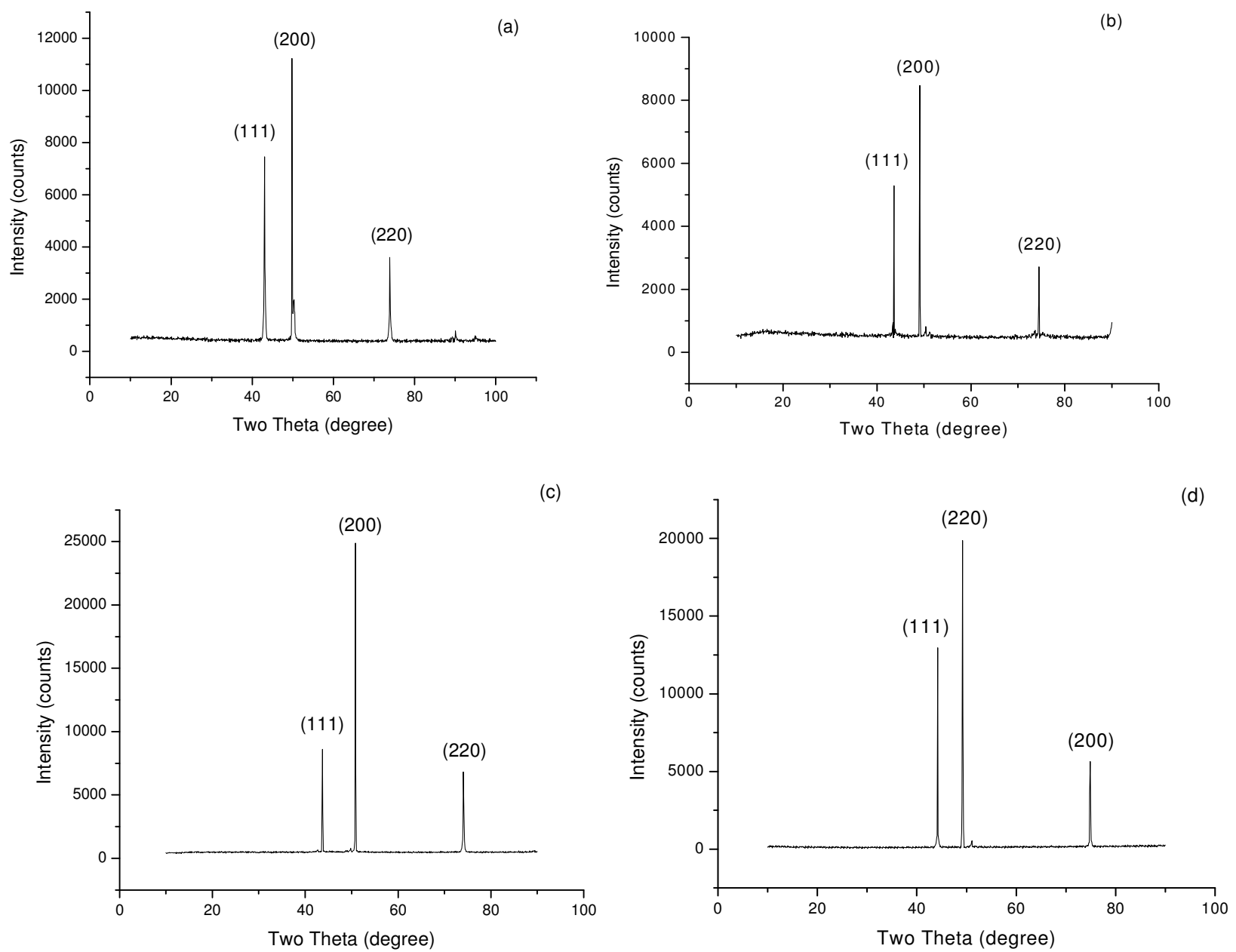

Fig.-5: NiFeP Alloy Films- XRD Patterns with Different Current Density (a) $2 \mathrm{~mA} / \mathrm{cm}^{2}$ (b) $3 \mathrm{~mA} / \mathrm{cm}^{2}$ (c) $4 \mathrm{~mA} / \mathrm{cm}^{2}$ (d) $5 \mathrm{~mA} / \mathrm{cm}^{2}$

The crystallite sizes, strain and dislocation density are tabulated in Table-1. The strain decreases as 1.201 $\times 10^{-3}, 0.980 \times 10^{-3}, 0.828 \times 10^{-3}$ and $0.709 \times 10^{-3}$ for current density $2,3,4$ and $5 \mathrm{~mA} / \mathrm{cm}^{2}$ respectively. While current density is increased from 2 to $5 \mathrm{~mA} / \mathrm{cm}^{2}$, the crystallite size increases because of decreasing in ferrous content during electro deposition process. Fig.-6 shows the variation of crystal size with increasing current density.

Table-1: NiFeP Alloy Films -Structural Properties

\begin{tabular}{c|c|c|c|c|c|c}
\hline S. No. & $\begin{array}{c}\text { Current density } \\
\left(\mathrm{mA} / \mathrm{cm}^{2}\right)\end{array}$ & $\begin{array}{c}2 \theta \\
(\mathrm{deg})\end{array}$ & $\begin{array}{c}\mathrm{d} \\
\left(\mathrm{A}^{0}\right)\end{array}$ & $\begin{array}{c}\text { Particle Size(D) } \\
(\mathrm{nm})\end{array}$ & $\begin{array}{c}\text { Strain } \\
\left(10^{-3}\right)\end{array}$ & $\begin{array}{c}\text { Dislocation Density } \\
\left(10^{14} / \mathrm{m}^{2}\right)\end{array}$ \\
\hline 1 & 2 & 49.83 & 1.904 & 30.15 & 1.201 & 11.01 \\
\hline 2 & 3 & 49.17 & 1.736 & 36.93 & 0.980 & 07.33 \\
\hline 3 & 4 & 50.82 & 1.852 & 43.73 & 0.828 & 05.23 \\
\hline 4 & 5 & 49.36 & 1.813 & 51.09 & 0.709 & 03.83 \\
\hline
\end{tabular}

\section{Mechanical Properties}

Micro hardness measurement of NiFeP deposits was done by Vickers hardness tester. The hardness values of thin films prepared with increasing current density are 109, 92, 73, 58 VHN respectively. 
Decreasing value of hardness is concluded due to increases in particle sizes. Figure-7 shows the variation of hardness with increasing current density.

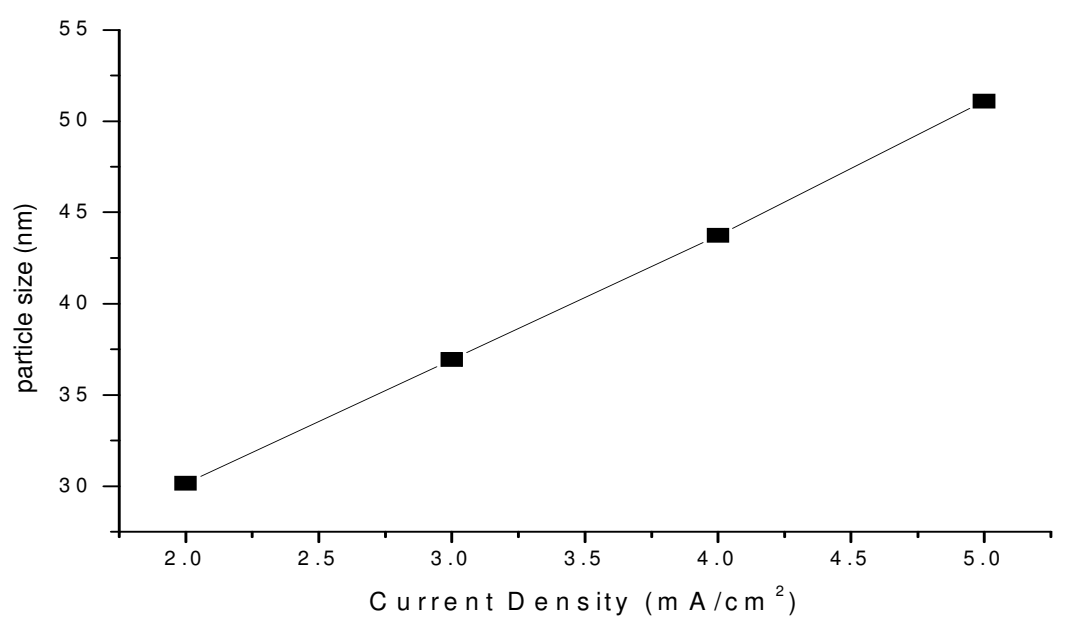

Fig.-6: Current Density Vs Crystal Size

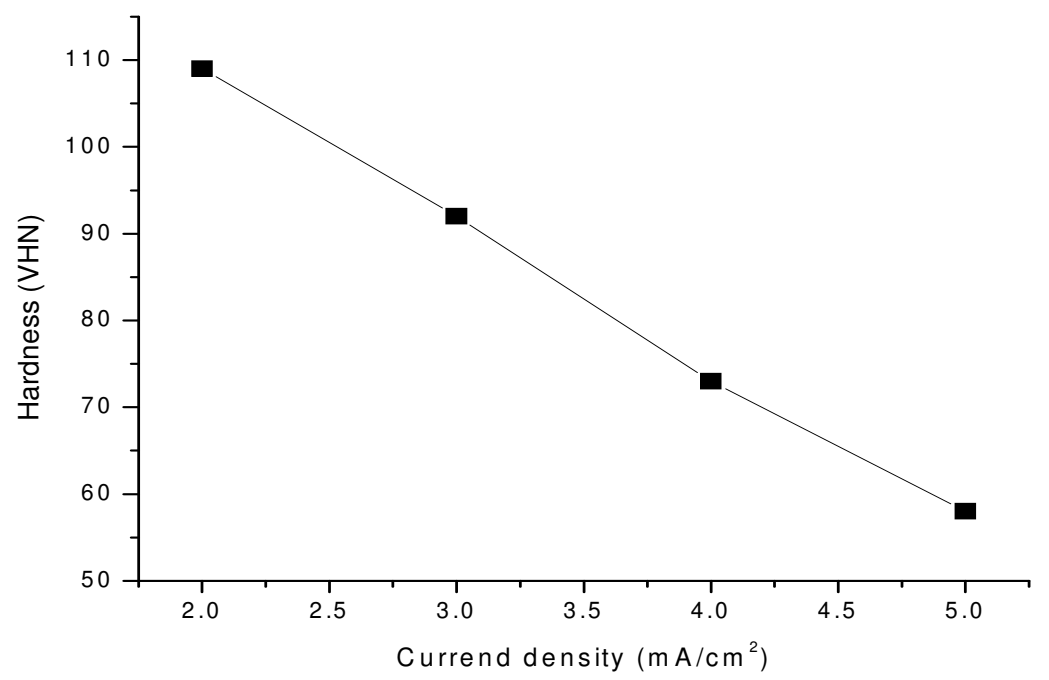

\section{Magnetic Characteristics}

Fig.-7: Current Density Vs Vickers Hardness

The hysteresis curves for Ni-Fe-P thin films for distinct current density 2,3,4 and $5 \mathrm{~mA} / \mathrm{cm}^{2}$ are shown in figure 8. It is noted that magnetization value decreases as $87.2 \times 10^{-3} \mathrm{emu} / \mathrm{cm}^{2}, 24.4 \times 10^{-3} \mathrm{emu} / \mathrm{cm}^{2}, 13.0$ x $10^{-3} \mathrm{emu} / \mathrm{cm}^{2}$ and $2.99 \times 10^{-3} \mathrm{emu} / \mathrm{cm}^{2}$ for current density $2,3,4$ and $5 \mathrm{~mA} / \mathrm{cm}^{2}$ respectively. So it is confirmed that the films received with a lower current density provide higher magnetization values. The coercivity value increases as $174 \mathrm{G}, 242 \mathrm{G}, 349 \mathrm{G}$ and $410 \mathrm{G}$ for current density $2,3,4$ and $5 \mathrm{~mA} / \mathrm{cm}^{2}$ respectively. The retentivity values are $13.4 \times 10^{-3} \mathrm{emu} / \mathrm{cm}^{2}, 2.78 \times 10^{-3} \mathrm{emu} / \mathrm{cm}^{2}, 5.09 \times 10^{-3} \mathrm{emu} / \mathrm{cm}^{2}$ and $0.97 \times 10^{-3} \mathrm{emu} / \mathrm{cm}^{2}$ for current density $2,3,4$ and $5 \mathrm{~mA} / \mathrm{cm}^{2}$ respectively. Squareness values are $0.1536,0.1139,0.3915$ and 0.3244 for current density $2,3,4$ and $5 \mathrm{~mA} / \mathrm{cm}^{2}$ respectively. Crystallite size of film deposits comes to a decision about magnetization and coercivity. If the grain size of magnetic materials is big, the domain wall movement confirms the magnetic characters of that materials. The magnetization value decreases by increasing current density. Also coercivity increases by increasing current density.

The grain size of deposits is increased by rising current density. Because of smaller crystalline size, NiFe-P thin films received with low current density $2 \mathrm{~mA} / \mathrm{cm}^{2}$ have higher saturation magnetization and low 
RASĀYAN J. Chem.

Vol. 11 | No. 3 |1144 - 1150 | July - September | 2018

coercivity. From results, it is confirmed that the best soft magnetic characters can be received with low current density.
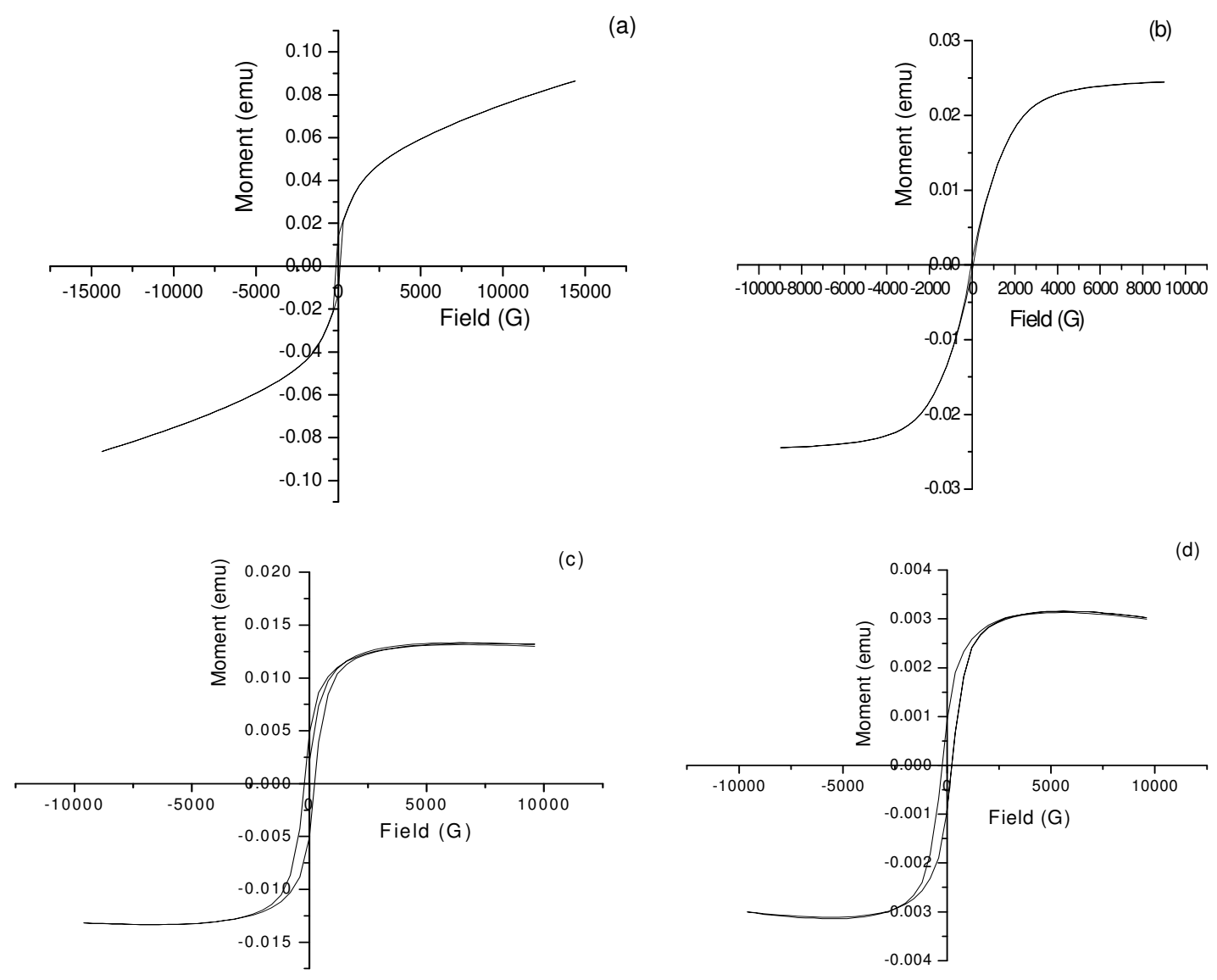

Fig.-8: NiFeP Thin Films - Magnetic Hysteresis Curves with Different Current Density (a) $2 \mathrm{~mA} / \mathrm{cm}^{2}$ (b) $3 \mathrm{~mA} / \mathrm{cm}^{2}$ (c) $4 \mathrm{~mA} / \mathrm{cm}^{2}$ (d) $5 \mathrm{~mA} / \mathrm{cm}^{2}$

\section{CONCLUSION}

An alloy thin films NiFeP have been prepared by electro deposition technique. The properties of NiFeP films were analyzed. EDAX result has indicated the increase in nickel content with an increase of current density. The high nickel composition of $80.81 \mathrm{wt} \%$ was found with current density $5 \mathrm{~mA} / \mathrm{cm}^{2}$. FCC phase is the nature of crystals which deposited on subtract and average size of particles is around $40 \mathrm{~nm}$. The thin films received with current density 2 to $5 \mathrm{~mA} / \mathrm{cm}^{2}$ are shiny and deposited uniformly on the surface. They appear to the crack-free surface. The micro hardness values of alloy films obtained with increasing current density are 109, 92, 73 and $58 \mathrm{VHN}$ respectively. The saturation magnetization value decreases from $87.2 \times 10^{-3} \mathrm{emu} / \mathrm{cm}^{2}$ to $2.99 \times 10^{-3} \mathrm{emu} / \mathrm{cm}^{2}$ when current density raises from 2 to $5 \mathrm{~mA} / \mathrm{cm}^{2}$. From results, it is confirmed that the best soft magnetic characters can be received with low current density.

\section{ACKNOWLEDGMENT}

The authors wish to acknowledge Dr. T. Baskar, Professor, Dept of Physics, Vidyaa Vikas College of Engineering and Technology, Tiruchengode, Tamilnadu, India for providing technical support.

\section{REFERENCES}

1. J.W. Judy, R.S. Muller and H.H. Zappe, IEEE J. Micro Electromech. Syst., 4, 162 (1995).

2. J.W. Judy and R.S. Muller, Sensors Actuators (Physical A) A., 53, 392 (1996). 
RASĀYAN J. Chem.

Vol. 11 | No. 3 |1144 - 1150 | July - September | 2018

3. R. Celine and F. Patrick, J. Mater .Sci., 46, 6046(2011), DOI: 10.1007/s10853-011-5566-9

4. C.H. Ahn and M.G. Allen, IEEE Trans. Ind. Electron., 45, 866 (1998).

5. M. Ghorbani, A. Dolati and A. Afshar, Russian Journal of Electrochemistry., 38, 1173 (2002) , DOI: 10.1023/A:1021141524584

6. N. Gupta ,A. Verma and S.C. Kashyap, Solid State Commun., 10, 689(2005).

7. X.F.Meng, D.H.Li, X.Q.Shen and W. Liu, Applied Surface Science, 256, 3753(2010), DOI: 10.1016/j.apsusc.2010.01.019.

8. Y. Motomura , T .Tatsumi , H. Urai and M. Aoyama, IEEE Trans. Magn., 26, 2327(1990).

9. S. Sam, G. Manavalan, A. Guittoum, N. Gabouze and S. Djebbar, Surf. Sci., 601, 4270(2007), DOI: 10.1016/j.susc.2007.04.107.

10. S. Esmaili, M.E Bahrololoom and C .Zamani, Process. Mater., 47, 10(2011).

11. H. J. Cho, S. Bhansali and C. H. Ahn , J.Appl. Phy., 87, 6340(2000), DOI: 10.1063/1.372699.

12. L. Chih-Huang, H. Matsuyama, R.L. White and T.C. Anthony, IEEE Transactions on Magnetics, 31(6), 2609(1995), DOI:10.1109/20.490068.

13. A. D. Romig and J. Goldstein, Metall. Trans. A., 11, 1151(1980).

14. K. Sridharan and K. Sheppard, J. Appl. Electrochem., 27, 1198 (1997), DOI:10.1023/A:1018475718629

15. Z.G An, J.J. Zhang and S.L. Pan, Applied Surface Science ., 255, 2219( 2008).

16. K. Baonkeup and Y. Bongyoung, Surf. Coat. Technol., 205, 740 (2010), DOI:10.1016/j.surfcoat.2010.07.076.

17. S.LWang, Surf. Coat. Technol., 186, 372(2004), DOI: 10.1016/j.surfcoat.2004.01.017

18. V. Nosang, D.Y. Park, B.Y. Yoob and T.A. Paulo, J. Magn. Mater., 265, 189(2003), DOI:10.1016/S0304-8853(03)00264-6.

19. X.H. Yan, J.Q. Sun, Y.W. Wang and J.F. Yang, Journal of Molecular Catalysis A: Chemical, 252, 17(2006), DOI:10.1016/j.molcata.2006.01.060.

20. G.V. Fernandez, P.J Grundy and M.M. Vopson, J. Phys, Condens. Matter, 1(1),6 (2013).

21. Z .Shi, K. Deng and L. Li , Sci. Rep., 5,9317 (2015), DOI:10.1038/srep09317.

22. R. Kannan, M. Selvambikai , I. Jeena Rajathy and S. Ananthi, Rasayan J. Chem.,10,1213(2017), DOI:10.7324/RJC.2017.1041925

[RJC-3088/2018] 